\title{
Circulating immune complexes in patients with ankylosing spondylitis
}

\author{
G. S. PANAYI, J. SLANEY, AND B. D. WILLIAMS* \\ From the Departments of Medicine and Rheumatology, Guy's Hospital Medical School, London SE1 9RT
}

SUMMARY EDTA plasma samples from 13 patients with ankylosing spondylitis (AS) were fractionated on Sephadex G-200 and the quantities of C3 and IgG within the first protein peak determined by a sensitive haemagglutination-inhibition assay. Seven patients with AS had C3 detectable in the first peak and this was associated with an increased concentration of IgG in the corresponding fraction. These 7 patients had more active disease but did not have more peripheral arthritis. Our results indicate that circulating immune complexes capable of initiating complement activation are present in the circulation of patients with ankylosing spondylitis.

Despite the striking association between ankylosing spondylitis (AS) and HLA B27 the role of immunological factors in the pathogenesis of the disease is not clear. Recently it has been proposed that AS may be related in some way to infection with Klebsiella pneuomoniae, a bacterium which may possess antigens cross-reacting with HLA B27. ${ }^{1}$

One way by which immune reactions may be involved in tissue damage in AS may be via the deposition of immune complexes. In a previous paper we presented evidence that immune complexes are present in the circulation of patients with this disease. The complexes were detected by the technique of inhibition of antibody-dependent cell-mediated cytotoxicity (ADCC). ${ }^{2}$ However, these complexes may not be of pathological importance, since they may not activate the complement system. Complement activation is an important mechanism for the induction of inflammation. There is some evidence that activation does occur in AS, since raised serum levels of $\mathrm{C} 3$ and $\mathrm{C} 4$ inactivation products have been noted. ${ }^{3}$ We therefore decided to investigate this possibility by measuring the amount of macromolecular C3 in EDTA-plasma of AS patients as evidence of complexed or activated complement.

\section{Materials and methods}

\section{PATIENTS}

Thirteen patients with AS were studied. The duration of disease, presence of morning stiffness, inflam-

Accepted for publication 14 September 1979

Correspondence to Dr G. S. Panayi,

*Present address, Department of Medicine, Royal Postgraduate Medical School, Ducane Road, London W13. mation in peripheral joints, and the erythrocyte sedimentation rate were noted. All patients were HLA B27 positive. None had active uveitis at the time of study.

\section{LABORATORY METHODS}

Collection and storage of plasma. Blood was collected into EDTA (final concentration $0.01 \mathrm{M}$ ), rapidly separated, aliquoted, and the plasma samples stored at $-70^{\circ} \mathrm{C}$ until used.

Macromolecular C3 assay (MMC3). Details of this method have already been published. ${ }^{4}$ Briefly, the method consists of fractionating EDTA-plasma on Sephadex G-200. The presence of MMC3 is indicated by a change in distribution in $\mathrm{C} 3$ with its appearance within the first peak of G-200 eluted fractions.

Plasma C3 and C4 levels. These were determined by radial immunodiffusion using monospecific anti-sera and results expressed as a percentage of a pool of normal plasma.

Detection of $\operatorname{IgG}$. The concentration of $\operatorname{IgG}$ in the various Sephadex G-200 fractions was determined by a microhaemagglutination assay. Washed, group O rhesus positive human red blood cells were sensitised with human anti-D serum and after 2 washings in Veronal-buffered saline were resuspended at $0.5 \%$ concentration. Sephadex G-200 eluted plasma fractions were serially diluted with buffer in plastic microtitre microagglutination trays, and an equal volume of an appropriate dilution of an anti-IgG antiserum (containing 2 minimum agglutinating doses) was added. After incubation at room temperature for 60 minutes the sensitised cells were 
added and allowed to settle overnight at $4{ }^{\circ} \mathrm{C}$. From the pattern of haemagglutination the presence and concentration of IgG in each fraction could be determined by reference to standard solutions of human IgG. The lowest concentration of IgG detectable by this method was $0 \cdot 2 \mu \mathrm{g} / \mathrm{ml}$.

\section{Results}

PLASMA CONCENTRATION OF C 3 AND C4 The plasma concentration of $\mathrm{C} 3$ and $\mathrm{C} 4$ was within the normal for all 13 patients studied irrespective of whether they had active disease as judged by the ESR, duration of morning stiffness, or inflamed peripheral joints (results not shown).

\section{MACROMOLECULAR C3 AND IgG}

The elution characteristics of $\mathrm{C} 3$ and IgG for a control normal plasma chromatographed on Sephadex G-200 is shown in Fig. 1A; C3 is not found

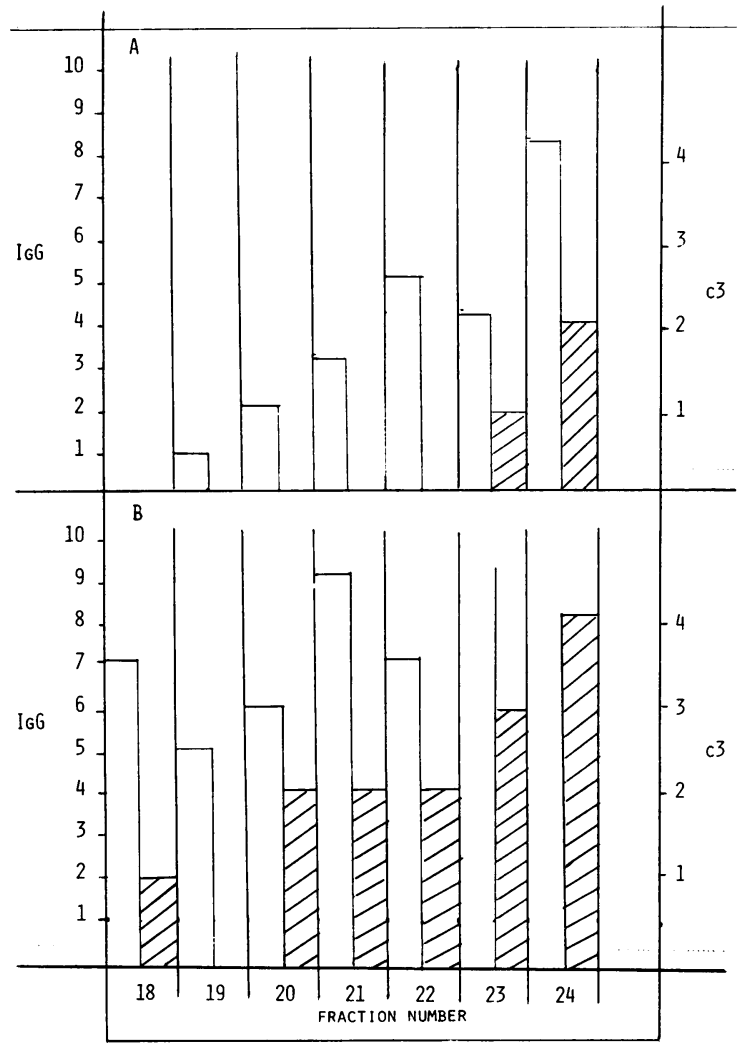

Fig. 1 The presence of IgG $(\square)$ and $C 3(\quad)$ in fractions of the first peak from Sephadex G-200. In A is shown the elution profile for EDTA-plasma of normal control subject 1. In B is shown the elution profile for EDTA-plasma of AS patient 8. in fractions earlier than number 23 , while $\operatorname{IgG}$ is present in decreasing concentrations up to the void volume (fraction number 18 ). The elution profile $\vec{\Rightarrow}$ of the first peak for EDTA-plasma from a patient $\stackrel{\oplus}{\rightarrow}$ with AS is shown in Fig. 1B; C3 is present in early fractions, including the void volume (fraction 18), while the concentration of IgG is much higher than in the corresponding control plasma. IgG is present in the first peak of fractionated control plasma, but the concentrations are higher in the AS group. Indeed, the highest first peak IgG concentration is found in the MMC3 group.

Macromolecular C3 was not found in the plasma of 6 healthy controls beyond fraction 22 but was found in 7 of 13 patients $(54 \%)$. The results for MMC3. and IgG are shown in Table 1. In Table 2 are shown in summary form some of the clinical details for these 2 groups of spondylitic patients. There is no difference in the duration of disease between them and the amount of inflammatory joint disease, though the group with more MMC3 have a more elevated ESR and more prolonged morning stiffness. Since none of the patients had uveitis, it was not possible to ascertain whether there is any relationship between this complication an the presence of immune complexes.

Table 1 Summary of the results for the presence and concentrations of macromolecular C3 (MMC3) found in the fractions of the first peak of Sephadex G-200. There were 6 control subjects. The 13 AS patients are divided into 2 groups: numbers 1-6 inclusive are negative for $M M C 3$, while numbers 7-13 are positive for $M M C 3$. The first number under each column fraction represent the concentration of $\operatorname{IgG}$ and the second number the concentration of $C 3$ as a reciprocal of the inhibition titre. One well of inhibition $=0.2 \mu \mathrm{g} \operatorname{IgG}$ or $C 3$, two wells of inhibition $0.4 \mu \mathrm{g} \operatorname{IgG}$ or $C 3$ and so on.

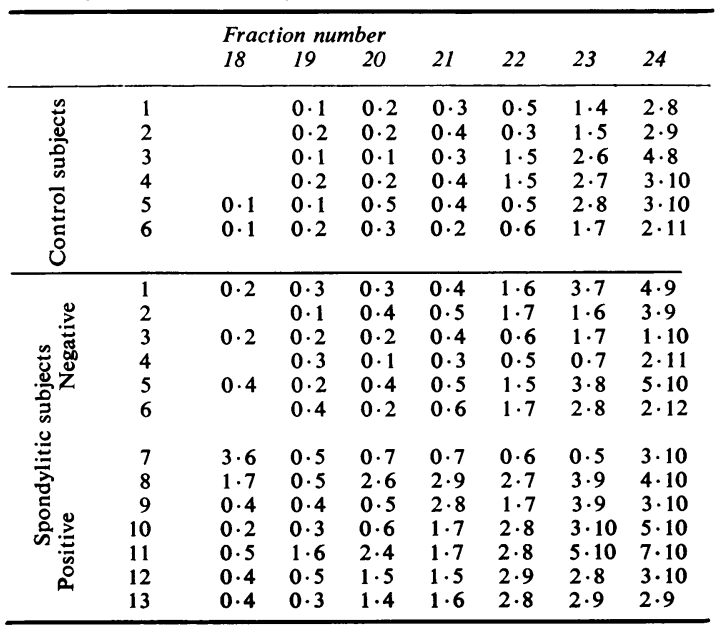


Table 2 Clinical details of the 2 groups of patients with ankylosing spondylitis. Patients are divided into 2 groups on the distribution of $C 3$ in the first protein peak obtained by fractionation on Sephadex G-200.

\begin{tabular}{|c|c|c|c|c|c|}
\hline $\begin{array}{l}\text { Patient } \\
\text { group }\end{array}$ & $\begin{array}{l}\text { Patient } \\
\text { number }\end{array}$ & $E S R$ & $\begin{array}{l}\text { EMS } \\
\text { (hour) }\end{array}$ & $\begin{array}{l}\text { Number of } \\
\text { joints involved }\end{array}$ & $\begin{array}{l}\text { Duration of } \\
\text { disease } \\
\text { (years) }\end{array}$ \\
\hline 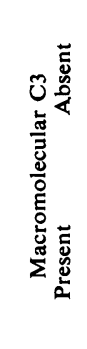 & $\begin{array}{r}1 \\
2 \\
3 \\
4 \\
5 \\
6 \\
\\
7 \\
8 \\
9 \\
10 \\
11 \\
12 \\
13\end{array}$ & $\begin{array}{r}42 \\
70 \\
25 \\
37 \\
24 \\
\\
30 \\
15 \\
30 \\
9 \\
15 \\
17 \\
30\end{array}$ & $\begin{array}{l}1 \cdot 0 \\
2 \cdot 0 \\
1 \cdot 0 \\
1 \cdot 0 \\
0 \\
0 \\
\\
0 \cdot 5 \\
0 \\
0 \\
0 \cdot 5 \\
1 \cdot 0 \\
0 \\
0\end{array}$ & $\begin{array}{l}0 \\
7 \\
0 \\
0 \\
1 \text { hip + several } \\
0 \\
1 \text { knee } \\
1 \text { knee } \\
2 \\
1 \\
0 \\
0 \\
0\end{array}$ & $\begin{array}{r}6 \\
32 \\
11 \\
19 \\
2 \\
21 \\
11 \\
\\
32 \\
3 \\
12 \\
4 \\
14 \\
20 \\
20\end{array}$ \\
\hline
\end{tabular}

\section{Discussion}

Activation of the complement system via the classical or alternative pathway changes the molecular weight of a proportion of the $\mathrm{C} 3$ present in serum. Some of the $\mathrm{C} 3$ binds to the activating agent, but the remainder binds either to other complement components or to other serum protein. Changes in the molecular weight of $\mathrm{C} 3$ are reflected in a change in the distribution and usually the amount of $\mathrm{C} 3$ in the first peak of G-200 fractionated plasma. One of the advantages with this assay is that it may detect complement activation triggered through either pathway. The generation of either classical or alternative pathway convertases, with the cleavage of large numbers of $\mathrm{C} 3$ molecules and the amplification effects of $\mathrm{C} 3 \mathrm{~b}$ on the feedback loop of the alternative pathway, may account for the sensitivity of the assay in detecting small amounts of immune complexes. Nonspecific activation of the complement system in vitro can be prevented by collecting the blood samples into EDTA.

The use of this assay in clinical situations is limited by the time taken to fractionate the samples. However, when compared with other assays used to detect immune complexes good correlations have been observed. In Hodgkin's disease a close correlation was found between positive macromolecular $\mathrm{C} 3$ assay and the $\mathrm{Clq}$ binding assay in symptomatic and asymptomatic patients, and it provided a more sensitive indicator of complement activation than the plasma C3d levels. ${ }^{56}$ Further, in Behçet's disease a similar proportion of patients with circulating immune complexes was observed irrespective of whether the MMC3 or latex inhibition assay was used. ${ }^{78}$ Both assays also found a higher proportion of immune complexes in patients with neuro-ocular and arthritic types of Behçet's disease.

This study shows that material containing IgG and MMC3 is found in EDTA-plasma samples of some $50 \%$ of patients with AS. One explanation for these findings is that they are due to circulating immune complexes. A similar proportion of patients were found to have circulating immune complexes by the inhibition of ADCC, a technique which does not depend on complement components. ${ }^{2}$ Chromatography on Sephadex G-200 revealed a wide range of molecular weights for such complexes, and this observation has been confirmed in this study.

Although the results are consistent with the idea that immune-complex-triggered activation of the complement system occurs in patients with AS, other explanations are possible. The raised ESR and more active disease in the positive group may be accompanied by high $\mathrm{C} 3$ and factor B levels (both are acute-phase proteins), which may potentiate the feedback mechanisms which give rise to $\mathrm{C} 3$ conversion. We believe that this is not the explanation for our findings, since 3 of the samples in the control group were obtained from patients who had undergone surgery 3-5 days previously and in whom rises of acute-phase proteins were present without the presence of MMC3.

Material behaving as immune complexes has been described as being present in the serum or plasma of patients by other investigators. ${ }^{3910}$ Some of these methods have involved analysis of changes in the complement system. Gabay et al. ${ }^{11}$ found complexes by the ${ }^{125} \mathrm{I}-\mathrm{Clq}$ binding test and $\mathrm{C} 3 \mathrm{~d}$ conversion product in AS patients who were seropositive for IgM rheumatoid factor. None of our patients had rheumatoid factor. Our results are certainly consistent with the idea that immune-complex-triggered activation of the complement system is occurring in patients with ankylosing spondylitis.

Further aspects of the role of immune complexes in AS are worthy of study: first, whether the presence of complexes can be used to predict disease relapse; secondly, the role of complexes in the pathogenesis of extraspinal disease manifestations such as arthritis and uveitis; finally the nature of any extraneous antigen composing these complexes and its relationship to postulated aetiological agents such as Klebsiella.

The study was financed by a grant from the Arthritis and Rheumatism Council.

\section{References}

1 Ebringer R W, Cawdell D R, Cowling P, Ebringer A. Sequential studies in ankylosing spondylitis. Association of Klebsiella pneumoniae with active disease. Ann Rheum Dis 1978; 37: 146-51. 
2 Corrigall V, Panayi G S, Unger A, Poston R N, Williams B D. Detection of immune complexes in serum of patients with ankylosing spondylitis. Ann Rheum Dis 1978; 37: 159-163.

3 Sturrock R D, Barrett A J, Versey J, Renolds M. Raised levels of complement inactivation products in ankylosing spondylitis. J Rheumatol 1974; 1 : 428-31.

4 Williams B D, Slaney J M. (1977). Macromolecular C3: an indirect marker of circulating immune complexes. Ann Rheum Dis 1977; 36: (suppl. 1), 37-9.

5 Amlot P L, Slaney J M, Williams B D. Circulating immune complexes and symptoms in Hodgkin's disease. Lancet 1976; 1: 449-51.

6 Amlot P L, Pussell B, Slaney J M, Williams B D. Correlation between immune complexes and prognostic factors in Hodgkin's disease. Clin Exp Immunol 1978; 31: $166-75$.
7 Williams B D, Lehner T. Immune complexes in Behçet's syndrome and recurrent oral ulceration. $\mathrm{Br} \mathrm{Med} J 1977$ 1: 1387-9.

${ }^{8}$ Levinsky R J, Lehner T. Circulating soluble immune complexes in recurrent oral ulceration and Behçet's syndrome. Clin Exp Immunol 1978; 32: 193-8.

9 Lurhuma A Z, Cambiaso C L, Masson P L, Heremans D. Detection of circulating antigen-antibody complexes by their inhibitory effect on the agglutination of IgG coated particles by rheumatoid factor or Clq. Clin Exp Immunol 1976; 25: 212-26.

10 Whaley K, Canesi B, Moseley A, et al. Complement metabolism in the seronegative arthritides. Ann Rheum Dis 1974; 33: 495-9.

11 Gabay R, Zubler R H, Nydegger V E, Lambert P H. Immune complexes and complement catabolism in ankylosing spondylitis. Arthritis Rheum 1977; 20: 913-6. 